\title{
Speed and Current Sensor Fault Detection and Isolation Based on Adaptive Observers for IM Drives
}

\author{
Yong $\mathrm{Yu}^{\dagger}$, Ziyuan Wang*, Dianguo Xu*, Tao Zhou ${ }^{*}$, and Rong $\mathrm{Xu}^{*}$ \\ $\dot{\dagger}^{*}$ Department of Electrical Engineering, Harbin Institute of Technology, Harbin, China
}

\begin{abstract}
This paper focuses on speed and current sensor fault detection and isolation (FDI) for induction motor (IM) drives. A new, accurate and high-efficiency FDI approach is proposed so that a system can continue operating with good performance even in the presence of speed sensor faults, current sensor faults or both. The proposed three paralleled adaptive observers are capable of current sensor fault detection and localization. By using observers, the rotor flux and rotor speed can be estimated which allows the system to run under the speed sensorless vector control mode when a speed sensor fault occurs. In order to detect speed sensor faults, a threshold-based scheme is proposed. To verify the feasibility and effectiveness of the proposed FDI strategy, experiments are carried out under different conditions based on a dSPACE DS1104 induction motor drive platform.
\end{abstract}

Key words: Adaptive observer, Current sensor, Fault Detection and Isolation (FDI), Induction Motor (IM), Speed sensor

\section{NOMENCLATURE}

$R_{s}\left(R_{r}\right) \quad$ Stator (rotor) resistance $(\Omega)$.

$L_{s}\left(L_{r}\right) \quad$ Stator (rotor) self-inductance $(\mathrm{H})$.

$L_{m} \quad$ Mutual inductance $(\mathrm{H})$.

$\omega_{r} \quad$ Rotor electrical speed $(\mathrm{rad} / \mathrm{s})$.

$\sigma=1-L_{m}^{2} /\left(L_{s} L_{r}\right) \quad$ Leakage coefficient.

$\boldsymbol{i}=\left[\begin{array}{ll}i & i\end{array}\right]^{T} \quad$ Stator current vector in the stationary $\alpha-\beta$

reference frame (A).

$\hat{\psi}=\left[\begin{array}{lll}\psi & \psi\end{array}\right]^{T} \quad$ Rotor flux vector in the stationary $\alpha-\beta$

$\psi_{r}\left[\begin{array}{lll}W_{n} & W_{r \beta}\end{array}\right]$ reference frame $(\mathrm{Wb})$

$\boldsymbol{u}_{s}=\left[\begin{array}{ll}u_{s \alpha} & u_{s \beta}\end{array}\right]^{T} \quad$ Stator voltage vector in the stationary $\alpha-\beta$ reference frame $(\mathrm{V})$.

\section{INTRODUCTION}

During the past decade, the reliability and safety of electric-motor drive systems, especially in high-risk applications, have drawn the attention of many researchers. Fault detection and isolation (FDI) or fault tolerant control (FTC), which aims to detect faults and to keep a system

Manuscript received Jan. 18, 2014; accepted Jun. 11, 2014

Recommended for publication by Associate Editor Kwangwoon Lee.

${ }^{\dagger}$ Corresponding Author: yuyong@hit.edu.cn

Tel: +86-451-86413420, Harbin Institute of Technology

${ }^{*}$ Dept. of Electronic Eng., Harbin Institute of Technology, China running continuously after faults have occurred, has become a very active research field.

There are three main kinds of faults in induction motor drive systems: electrical faults, such as stator faults (openphase, short-circuit, electrical discharges, etc.) [1], [2], rotor faults (broken bar or cracked end-ring) [3], [4], and inverter faults (short-circuit and open-circuit) [5]; mechanical faults, such as bearing faults [6], [7] and eccentricity faults [8], [9]; and sensor faults. A lot of studies have been published on the diagnostic techniques of electrical and mechanical faults and an overview of these techniques is given in [10].

On the controller side, sensor faults are one of the most common problems in industrial applications [11]. Fig. 1 shows the structure of the most widely used voltage source inverter (VSI) fed induction motor drive system. In this system, it can be seen that a speed sensor, a DC-link voltage sensor and two or three current sensor are utilized. The fault detection and isolation of these sensors are of great importance since their failure can lead to a drive failure. In recent years, a growing number of researchers have dedicated themselves to the study of this topic.

In case of speed sensor faults, the most common method is to utilize the estimated speed obtained from a speed observer instead of the measured speed [12]. From [11]-[15], it can be seen that many kinds of observers can be used, such as 


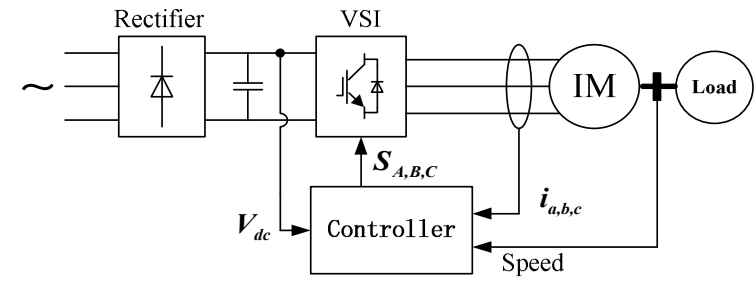

Fig. 1. Structure of the VSI-fed induction motor drive system.

Luenberger observers, adaptive observers, sliding-mode observers, MRAS observers, Kalman filters, etc. However, most researchers focus on the design of speed observers while the detection and isolation of speed sensor faults in induction motor drive systems is seldom studied and published works are rare.

The authors of [16] presented an inexpensive and effective speed sensor fault diagnosis technique based on fuzzy logic. However, since this technique is based on an accurate analysis of the recorded data or information, a large data volume is needed to generate reliable and feasible fuzzy rules and these fuzzy rules should be modified or extended by new data, which is the main drawback of this technique. In [17], the relative speed ratio of the difference between the present speed and the speed of the last control period is calculated to detect the speed sensor fault. If the relative speed ratio exceeds a certain threshold, a speed sensor fault is detected. However, the reliability of this approach is under consideration, since, in the start-up, acceleration, deceleration, loading or unloading procedure, the motor speed may change a lot which can lead to a misinterpretation.

In the case of current sensor faults, the most popular approach is based on Kirchhoff's law, that is, if a current sensor fault occurs, the sum of the measured a, b, and c phase currents will no longer be equal to zero. Based on this theory, a multi-sensor switching strategy based on adaptive observers is proposed in [18]. Using the proposed switching mechanism, the measurements from faulty current sensors are automatically avoided. As a result, the induction motor drive system can maintain a good performance level in the presence of a faulty sensor. However, a speed sensor fault diagnosis and isolation scheme is not considered, and the strategy is only verified by simulation experiments under realistic conditions. In an effort to extend and supplement this research, this paper incorporates the LPF time constant selection technique, threshold determination, and a speed sensor fault diagnosis and tolerant control scheme.

A current and voltage sensor fault detection and isolation algorithm based on dynamic redundancy equations and the parity space approach for electric motor dive systems is proposed in [19]. The residual is generated automatically from sensor output values using parity equations and it is analyzed under healthy and sensor fault modes to determine the value of the threshold. If the residual is larger than the threshold, a sensor fault can be detected. A reconfiguration strategy is proposed based on Kirchhoff's law to ensure continuous operation under a faulty ac current sensor. This FDI algorithm is easy and fast. One drawback of this method it that only sudden faults can be detected since the algorithm is available for sensor measuring variables. Speed sensor faults are not discussed in this FDI algorithm. However, this algorithm is very important because speed sensor faults can lead to a wrong diagnosis of current sensor faults.

In [11], a detection and isolation technique for speed, DClink voltage and current sensor faults based on an adaptive observer with rotor-resistance estimation is presented. The main idea is to isolate all of the sensor faults with only one current observer. Unlike the methods which only consider the FDI of a particular sensor, all three types of sensors are studied at the same time. However, this technique is based on the assumption that only one sensor may be faulty during motor operation, which is unreasonable because the number of sensor faults that may happen during motor operation is unpredictable. Another drawback of this strategy is that the reconfiguration approach after sensor faults occurrence, which is vital for the performance of the induction motor drive system, is not covered.

From the studies analyzed above, it can be seen that the detection and isolation of sensors faults in electric motor drive systems still remains a challenging task for researchers and that a lot more work needs to be done. Therefore, this paper focuses on speed and current sensor fault diagnosis and an isolation technique in induction motor drive systems. This is done with the aim of detecting both kinds of sensor fault simultaneously and keeping the system running with good performance after one or two sensor fault has occurred. To diagnose speed sensor faults, a threshold-based scheme is proposed and an adaptive observer is designed based on the Lyapunov theory. Using the observer, the rotor speed and rotor flux can be estimated and the motor drive system can be switched to speed sensorless control mode in the case of speed sensor failures. To detect current sensor faults, a fault diagnosis approach based on three parallel adaptive observers is adopted. Then, a unified criterion for sensor faults is summarized. Finally, to verify the validity of the proposed scheme, a dSPACE based experiment is implemented on a $1.1 \mathrm{kw}$ induction motor.

\section{FAULT DETECTION AND ISOLATION UNIT DESIGN}

In this section, a novel speed and current sensor fault detection and isolation unit for induction motor drive systems is proposed. An induction motor drive system incorporated with the proposed current and speed sensors FDI unit is shown in Fig.2. It operates in vector controlled mode with speed information feedback in healthy speed and current sensors conditions. In the case of a current sensor fault occurrence, its fault can be detected, localized, and isolated, 


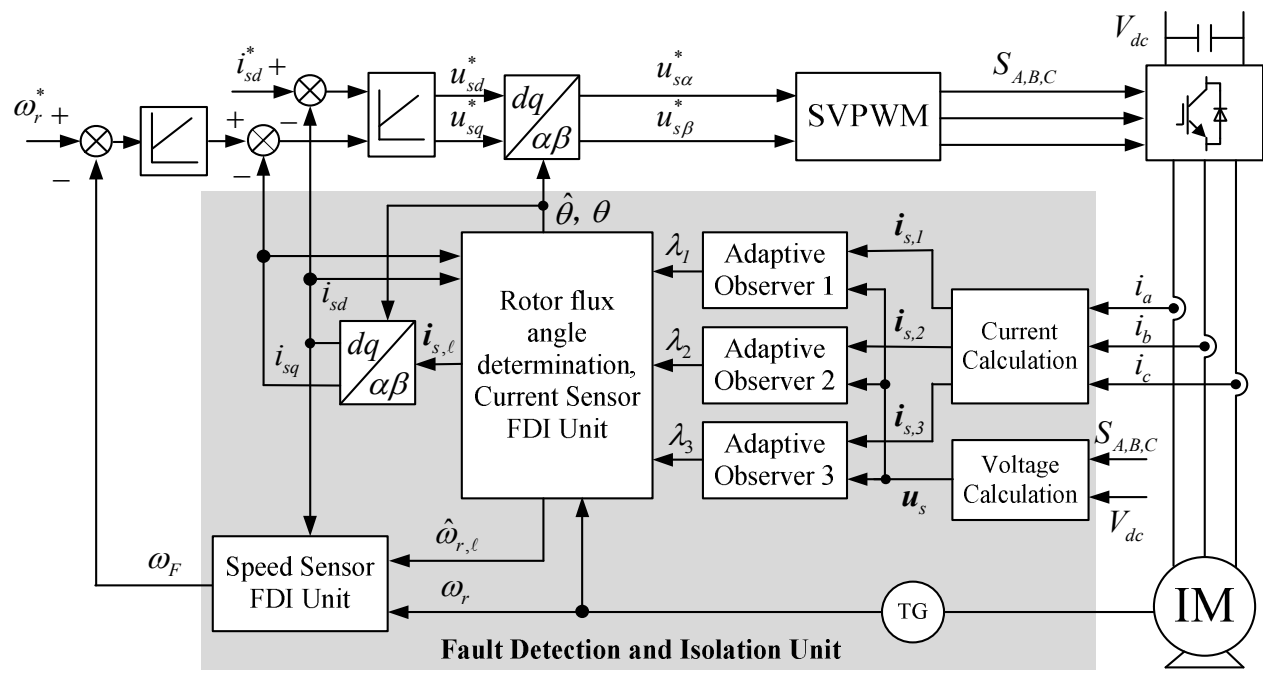

Fig. 2. Induction motor drive system with the proposed FDI Unit.

$*=$ Reference Value; $^{\wedge}=$ Estimated Value

and system will continue operates in vector controlled mode with the other two healthy current sensors and speed sensor. In case of speed sensor fault occurrence, its fault can also be detected and isolated, and the system will transfer to speed sensorless vector control mode. As a result, the system can obtain speed senor fault tolerance capability. The FDI unit consists of a current sensor FDI unit, a speed sensor FDI unit and three parallel adaptive observers in which the stator currents, rotor fluxes and rotor speed are estimated. The inner structures of the three observers are all the same and will be designed later. Each observer is fed by corresponding stator currents $\left(\boldsymbol{i}_{s, \ell}, \ell=1,2,3\right)$ and stator voltages $\left(\boldsymbol{u}_{s}\right)$ which are calculated by the current and voltage calculation units.

The output variables of the observers $\left(\lambda_{\ell}, \ell=1,2,3\right)$ are sent to the current sensor FDI unit which identifies the faulty current sensor and reconfigures the system to ensure continuous operation. The estimated rotor speed, measured rotor speed and $i_{s d}$ are sent to the speed sensor FDI unit to detect the speed sensor fault and keep the system running continuously under a faulty speed sensor. In the following sections, the adaptive observers, the current sensor FDI unit and the speed sensor FDI unit will be introduced.

\section{A. Introduction of the Adaptive Obsever}

In this section, a full order Lyapunov-based observer is adopted to estimate the stator currents, rotor fluxes and rotor speed. This observer was first proposed by H. Kubota ${ }^{[20]}$. It is based on a three-phase induction motor model in the stationary $\alpha-\beta$ reference frame. In the following paragraphs, the technical background will be introduced, and then the design of the observer gain matrix will be proposed.

1) Technical Back Ground ${ }^{[20]:}$ By choosing the stator currents and rotor fluxes as the state variables, and stator currents as the output variables, the state equation and output equation of the induction motor can be expressed as equation (1) and (2).

$$
\frac{d}{d t} \underbrace{\left[\begin{array}{c}
i_{s \alpha} \\
i_{s \beta} \\
\psi_{r \alpha} \\
\psi_{r \beta}
\end{array}\right]}_{\boldsymbol{x}}=\underbrace{\left[\begin{array}{cccc}
a_{1} & 0 & a_{2} & a_{3} \omega_{r} \\
0 & a_{1} & -a_{3} \omega_{r} & a_{2} \\
a_{4} & 0 & a_{5} & -\omega_{r} \\
0 & a_{4} & \omega_{r} & a_{5}
\end{array}\right]}_{\boldsymbol{A}\left(\omega_{r}\right)}\left[\begin{array}{l}
i_{s \alpha} \\
i_{s \beta} \\
\psi_{r \alpha} \\
\psi_{r \beta}
\end{array}\right]+\underbrace{\left[\begin{array}{cc}
b & 0 \\
0 & b \\
0 & 0 \\
0 & 0
\end{array}\right]}_{\boldsymbol{B}}[\underbrace{u_{s \alpha}^{u_{s \beta}}}_{\boldsymbol{u}_{s}}
$$

where $a_{1}=-\frac{R_{r} L_{m}^{2}+R_{s} L_{r}^{2}}{\sigma L_{s} L_{r}^{2}}, a_{2}=\frac{L_{m} R_{r}}{\sigma L_{s} L_{r}^{2}}, a_{3}=\frac{L_{m}}{\sigma L_{s} L_{r}}, a_{4}=\frac{L_{m} R_{r}}{L_{r}}$, $a_{5}=-\frac{R_{r}}{L_{r}}, b=\frac{1}{\sigma L_{s}}, \boldsymbol{C}=\left[\begin{array}{cccc}1 & 0 & 0 & 0 \\ 0 & 1 & 0 & 0\end{array}\right]$.

Structure of the proposed observer: The proposed full-order adaptive observer is based on the induction motor model in (1) and (2), as follow:

$$
\begin{aligned}
\frac{d}{d t} \hat{\boldsymbol{x}} & =\boldsymbol{A}\left(\hat{\omega}_{r}\right) \hat{\boldsymbol{x}}+\boldsymbol{B} \boldsymbol{u}+\boldsymbol{G}\left(\hat{\boldsymbol{i}}_{s}-\boldsymbol{i}_{s}\right) \\
\boldsymbol{G} & =\left[\begin{array}{llll}
g_{1} & g_{2} & g_{3} & g_{4} \\
g_{5} & g_{6} & g_{7} & g_{8}
\end{array}\right]^{T}
\end{aligned}
$$

where ${ }^{\wedge}$ represents estimated values, and $\boldsymbol{G}$ is the observer gain matrix. Fig. 3 shows the structure of the proposed adaptive observer.

Derivation of the adaptive scheme: The design of the adaptive scheme is crucial for the stability of the proposed observer. Here, Lyapunov's stability theorem is utilized to deduce it. By subtracting (3) from (1), the dynamics of the state estimation error can be obtained as Equation (5).

$$
\frac{d}{d t} \Delta \boldsymbol{x}=\left[\boldsymbol{A}\left(\omega_{r}\right)+\boldsymbol{G C}\right] \Delta \boldsymbol{x}+\Delta \boldsymbol{A} \hat{\boldsymbol{x}}
$$




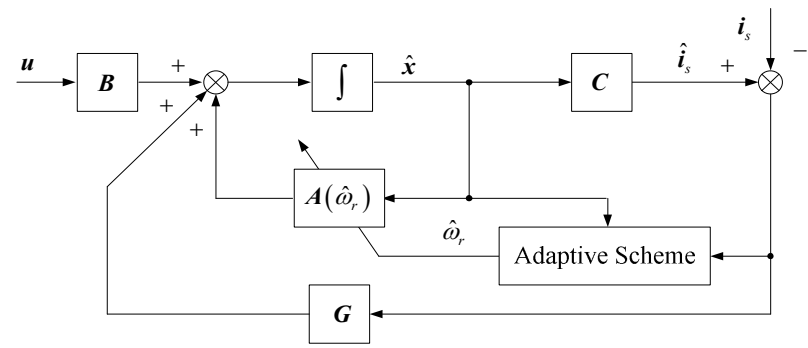

Fig. 3. Structure of the proposed adaptive observer.

where $\Delta \boldsymbol{x}=\boldsymbol{x}-\hat{\boldsymbol{x}}, \Delta \omega_{r}=\omega_{r}-\hat{\omega}_{r}$,

$$
\Delta \boldsymbol{A}=\boldsymbol{A}\left(\omega_{r}\right)-\boldsymbol{A}\left(\hat{\omega}_{r}\right)=\left[\begin{array}{cccc}
0 & 0 & 0 & a_{3} \Delta \omega_{r} \\
0 & 0 & -a_{3} \Delta \omega_{r} & 0 \\
0 & 0 & 0 & -\Delta \omega_{r} \\
0 & 0 & \Delta \omega_{r} & 0
\end{array}\right] .
$$

Then, the following Lyapunov function is chosen:

$$
\boldsymbol{V}=\Delta \boldsymbol{x}^{T} \Delta \boldsymbol{x}+\xi \Delta \omega_{r}^{2}
$$

in which $\xi$ is a positive constant. The time derivative of the Lyapunov function is as follow:

$$
\frac{d}{d t} \boldsymbol{V}=\Delta \boldsymbol{x}^{T} \boldsymbol{D} \Delta \boldsymbol{x}+2 \Delta \omega_{r} \varepsilon-2 \xi \Delta \omega_{r} \frac{d}{d t} \hat{\omega}_{r}
$$

where:

$$
\begin{gathered}
\boldsymbol{D}=\left[\boldsymbol{A}\left(\omega_{r}\right)+\boldsymbol{G} \boldsymbol{C}\right]^{T}+\left[\boldsymbol{A}\left(\omega_{r}\right)+\boldsymbol{G C}\right] \\
\boldsymbol{\varepsilon}=a_{3}\left(i_{s \alpha}-\hat{i}_{s \alpha}\right) \hat{\psi}_{r \beta}-a_{3}\left(i_{s \beta}-\hat{i}_{s \beta}\right) \hat{\psi}_{r \alpha}+\varepsilon_{\psi} \\
\varepsilon_{\psi}=\psi_{r \beta} \hat{\psi}_{r \alpha}-\psi_{r \alpha} \hat{\psi}_{r \beta}
\end{gathered}
$$

If the adaptive scheme is chosen to be:

$$
\frac{d}{d t} \hat{\omega}_{r}=\varepsilon / \xi
$$

The second and third terms in (7) are canceled out. Then, the Lyapunov function can be simplified as:

$$
\frac{d}{d t} \boldsymbol{V}=\Delta \boldsymbol{x}^{T} \boldsymbol{D} \Delta \boldsymbol{x}
$$

According to Lyapunov's stability theorem, if the observer gain matrix $\boldsymbol{G}$ is well-designed, the function in (12) can be negative-semidefinite. In other words, the proposed adaptive observer is stable.

As shown in (10), $\varepsilon_{\psi}$ contains the actual value of the rotor flux $\left(\psi_{r \alpha}, \psi_{r \beta}\right)$ which is difficult to measure. Assuming that the estimated value of the rotor flux is equal to the actual value, $\varepsilon_{\psi}$ can be neglected from (9). In order to accelerate the response of the speed estimation, the following PI adaptive scheme is adopted instead of (11).

$$
\hat{\omega}_{r}=\left(K_{P}+\frac{K_{I}}{s}\right)\left[\left(i_{s \alpha}-\hat{i}_{s \alpha}\right) \hat{\psi}_{r \beta}-\left(i_{s \beta}-\hat{i}_{s \beta}\right) \hat{\psi}_{r \alpha}\right]
$$

where $K_{P}$ and $K_{I}$ are positive gains.
2) Design of the Observer Gain Matrix: Since a three-phase induction motor is a nonlinear time-varing system and the observer poles change with the motor speed, the design of the observer gain matrix $\boldsymbol{G}$ is very complicated. Thus, a simple and practical design method is proposed according to the induction motor model.

Based on a steady state assumption, in order to simplify the design procedure, supposing that the speed estimation error $\Delta \omega_{r}=0$, the dynamics of the state estimation error (5) are equivalent to Equation (14), where $\Delta i_{s \alpha}=i_{s \alpha}-\hat{i}_{s \alpha}$, $\Delta i_{s \beta}=i_{s \beta}-\hat{i}_{s \beta}, \Delta \psi_{r \alpha}=\psi_{r \alpha}-\hat{\psi}_{r \alpha}, \Delta \psi_{r \beta}=\psi_{r \beta}-\hat{\psi}_{r \beta}$.

$$
\frac{d}{d t}\left[\begin{array}{c}
\Delta i_{s \alpha} \\
\Delta i_{s \beta} \\
\Delta \psi_{r \alpha} \\
\Delta \psi_{r \beta}
\end{array}\right]=\left[\begin{array}{cccc}
a_{1}+g_{1} & g_{5} & a_{2} & a_{3} \omega_{r} \\
g_{2} & a_{1}+g_{6} & -a_{3} \omega_{r} & a_{2} \\
a_{4}+g_{3} & g_{7} & a_{5} & -\omega_{r} \\
g_{4} & a_{4}+g_{8} & \omega_{r} & a_{5}
\end{array}\right]\left[\begin{array}{c}
\Delta i_{s \alpha} \\
\Delta i_{s \beta} \\
\Delta \psi_{r \alpha} \\
\Delta \psi_{r \beta}
\end{array}\right]
$$

Since the actual rotor flux is not available, by assuming that $\Delta \psi_{r \alpha}=0$ and $\Delta \psi_{r \beta}=0$, the following error differential equations can be obtained:

$$
\left\{\begin{array}{l}
\frac{d}{d t} \Delta i_{s \alpha}=\left(a_{1}+g_{1}\right) \Delta i_{s \alpha}+g_{5} \Delta i_{s \beta} \\
\frac{d}{d t} \Delta i_{s \beta}=g_{2} \Delta i_{s \alpha}+\left(a_{1}+g_{6}\right) \Delta i_{s \beta} \\
\frac{d}{d t} \Delta \psi_{r \alpha}=\left(a_{4}+g_{3}\right) \Delta i_{s \alpha}+g_{7} \Delta i_{s \beta} \\
\frac{d}{d t} \Delta \psi_{r \beta}=g_{4} \Delta i_{s \alpha}+\left(a_{4}+g_{8}\right) \Delta i_{s \beta}
\end{array}\right.
$$

To make the above error differential equations equal to zero, the unknown parameters in (15) are chosen as: $g_{1}=g_{6}=-a_{1}, g_{3}=g_{8}=-a_{4}$, and $g_{2}=g_{5}=g_{4}=g_{7}=0$. Thus, the observer gain matrix $\boldsymbol{G}$ is designed as Equation (16).

$$
\boldsymbol{G}=\left[\begin{array}{cccc}
-a_{1} & 0 & -a_{4} & 0 \\
0 & -a_{1} & 0 & -a_{4}
\end{array}\right]^{T}
$$

In summary, the proposed adaptive observer, which is utilized in the fault detection and isolation unit, is composed of Equations (3) and (13). The performance of the proposed observer will be tested in Section III.

\section{B. Current Sensor FDI Unit}

As shown in Fig. 2, the input signals of the current sensor FDI unit $\left(\lambda_{i}, i=1,2,3\right)$ are provided by three consistent adaptive observers. The only difference between the three observers are their input current $i_{s \alpha, n}$ and $i_{s \beta, n}(n=1,2,3)$.

Since the sum of phase currents $i_{s a}, i_{s b}$ and $i_{s c}$ is equal to zero:

$$
i_{s a}+i_{s b}+i_{s c}=0
$$

Any one phase current can be calculated from the other two, for example:

$$
\tilde{i}_{s c}=-i_{s a}-i_{s b}
$$

where $\tilde{i}_{s c}$ represents the calculated value of $i_{s c}$. 
Then, the input currents of observer 3 can be calculated from $i_{s a}, i_{s b}$ and $\tilde{i}_{s c}$ by the following equation:

$$
\left\{\begin{array}{l}
i_{s \alpha, 1}=(1 / 3)\left(2 i_{s a}-i_{s b}-\tilde{i}_{s c}\right) \\
i_{s \beta, 1}=(\sqrt{3} / 3)\left(i_{s b}-\tilde{i}_{s c}\right)
\end{array}\right.
$$

Similarly, the input currents of observer $2\left(i_{s \alpha, 2}\right.$ and $\left.i_{s \beta, 2}\right)$ can be calculated from $i_{s a}, i_{s c}$ and $\tilde{i}_{s b}$. The input currents of observer $1\left(i_{s \alpha, 3}\right.$ and $\left.i_{s \beta, 3}\right)$ can be calculated from $i_{s b}, i_{s c}$ and $\tilde{i}_{s a}$. Each observer outputs the following variable:

$$
\lambda_{j}=\left[\begin{array}{lllll}
i_{s \alpha, j} & i_{s \beta, j} & \hat{\psi}_{r \alpha, j} & \hat{\psi}_{r \beta, j} & \hat{\omega}_{r, j}
\end{array}\right]^{T}, j=1,2,3
$$

In order to diagnose current sensor faults, the following residual variable is considered ${ }^{[18]}$ :

$$
E_{j}=\overline{\overline{\hat{\psi}_{r, j}^{2}}-\left(\psi_{r}^{*}\right)^{2}+\left|\overline{\hat{\omega}_{r, j}}-\omega_{r}^{*}\right|}, j=1,2,3
$$

where $\hat{\psi}_{r, j}$ is the estimated rotor flux, $\psi_{r}^{*}$ is the rotor flux reference, $\hat{\omega}_{r, j}$ is the estimated motor speed, $\omega_{r}^{*}$ is the motor speed reference and $\hat{\psi}_{r, j}^{2}=\hat{\psi}_{r \alpha, j}^{2}+\hat{\psi}_{r \beta, j}^{2}$. The bars over the signals denote their filtered values, which are obtained by passing each signal through a low-pass filter ${ }^{[18]}$. The transfer functions of the filters are as follows:

$$
H_{n}(s)=\frac{1}{\tau_{n} s+1} \quad, \quad n=1,2,3
$$

where $H_{1}(s)$ is the filter for $\hat{\psi}_{r, j}^{2}, H_{2}(s)$ is the filter for $\hat{\omega}_{r, j}$, and $H_{3}(s)$ is the filter for $E_{j}$.

When the induction motor control system is stable, the values of $E_{j}$ will be close to zero. As what has been analyzed above, for instance, the input currents of observer $2\left(i_{s \alpha, 2}\right.$ and $\left.i_{s \beta, 2}\right)$ are calculated from $i_{s a}$ and $i_{s c}$. If a b-phase current sensor fault occurres, the output variable of observer $2\left(\lambda_{2}\right)$ will not be affected and $E_{2} \approx 0$. However, $E_{1}$ and $E_{3}$ will grow a lot. Things are similar for a-phase and c-phase current sensor faults. These facts are the basis of current sensor fault diagnosis and localization.

Thus, the scheme of the current sensor FDI unit can be described as follows:

I. If $E_{1}>E_{3}$ and $E_{2}>E_{3}, \ell=3$ is defined. Under this premise, if $E_{1}-E_{3}>F_{C}$, an $a$ phase current sensor fault is detected, then $I_{\text {Flag }}=1$ is defined.

II. If $E_{1}>E_{2}$ and $E_{3}>E_{2}, \ell=2$ is defined. Under this premise, if $E_{1}-E_{2}>F_{c}$, a $b$ phase current sensor fault is detected, then $I_{\text {Flag }}=1$ is defined.

III. If $E_{2}>E_{1}$ and $E_{3}>E_{1}, \ell=1$ is defined. Under this premise, if $E_{2}-E_{1}>F_{C}$, a $c$ phase current sensor fault is detected, then $I_{\text {Flag }}=1$ is defined.

IV. Finally, the current sensor FDI unit will transfer $\hat{\omega}_{r, \ell}$, $i_{s \alpha, \ell}$ and $i_{s \beta, \ell}$ to the speed sensor FDI unit and park transform module at each moment, which are obtained from an observer with healthy current sensors.

$I_{\text {Flag }}$ is the current sensor fault flag. $I_{\text {Flag }}=0$ means that a current sensor fault does not occur, and $I_{\text {Fag }}=1$ means that a current sensor fault is detected. $F_{c}$ is the current sensor fault threshold. Since the observer is based on a closed loop scheme, if a current sensor fault occurs, the corresponding observer will no longer converge, and its output will get larger. Experiment shows that this current FDI unit is able to detect faults without misinterpretation, and at the same time, it is able to implements smooth fault isolation.

\section{Speed Sensor FDI Unit}

Before the occurrence of a speed sensor fault, the induction motor control system is based on a vector controlled algorithm with speed sensor feedback. The rotor flux angle can be obtained by the integration of $\omega_{\mathrm{e}}$, where:

$$
\omega_{\mathrm{e}}=\omega_{\mathrm{r}}+\frac{i_{s q}}{T_{r} i_{s d}}
$$

After a speed sensor fault is detected, the rotor flux angle is obtained in a direct way, as shown in Equation (24).

$$
\hat{\theta}=\arctan \left(\frac{\hat{\psi}_{r \beta, \ell}}{\hat{\psi}_{r \alpha, \ell}}\right)
$$

In a normal situation, the $\mathrm{d}$ axis current $i_{s d}$ has a close relationship with the rotor flux angle $\theta$, which will be severely affected by the speed information obtained from the speed sensor. Therefore, at the instant of speed sensor fault occurrence, the $\mathrm{d}$ axis current $i_{s d}$ will depart from the reference value $i_{s d}^{*}$. In order to diagnose the speed sensor fault, the following residual variable is considered:

$$
\sigma=i_{s d}-i_{s d}^{*}
$$

When the system is stable, the mean value of $\sigma$ is close to zero. However, if a speed sensor failure occurs, the balance of the system will be broken and the error variable $\sigma$ will be influenced. Similarly, the $\mathrm{q}$ axis current $i_{s \mathrm{q}}$ will also be influenced by a speed sensor failure. However, when compared with $i_{s d}$, it is more sensitive to load changes. Anyway, a low-pass filter must be applied to $\sigma$, in order to extract the useful signal.

The transfer function of the filter is as follows:

$$
H_{4}(s)=\frac{1}{\tau_{4} s+1}
$$

where $\tau_{4}$ is a time constant, which should be chosen to achieve a low cutoff frequency LPF.

$\bar{\sigma}$ is used to represent the filtered signal of $\sigma$. If the system is stable, $\bar{\sigma} \approx 0$. When a speed sensor fault occurs, the value of $\bar{\sigma}$ becomes larger. The speed sensor is considered to be broken if $\bar{\sigma}$ satisfies the following criterion:

$$
\bar{\sigma}>F_{s}
$$


TABLE I

CRITERION FOR THE SENSOR FAULT

\begin{tabular}{|c|c|}
\hline Sensor Fault Type & Criterion \\
Speed sensor & $S_{\text {Flag }}=1$ \\
A-phase current sensor & $\ell=3$ and $I_{\text {Flag }}=1$ \\
B-phase current sensor & $\ell=2$ and $I_{\text {Flag }}=1$ \\
C-phase current sensor & $\ell=1$ and $I_{\text {Flag }}=1$ \\
No sensor fault & $S_{\text {Flag }}=0$ and $I_{\text {Flag }}=0$ \\
\hline
\end{tabular}

where $F_{s}$ is the speed sensor fault threshold.

The scheme of the speed sensor FDI unit is very simple:

- If $\bar{\sigma}>F_{s}$, define $S_{F l a g}=1$ and $\omega_{F}=\hat{\omega}_{r}$.

- If $\bar{\sigma} \leq F_{s}$, define $S_{\text {Flag }}=0$ and $\omega_{F}=c_{1} \omega_{r}+c_{2} \hat{\omega}_{r}$.

Where $\omega_{F}$ is the output of the speed sensor FDI unit which will be used as feedback to the controller, $c_{1}$ and $c_{2}$ are positive factors and $c_{1}+c_{2}=1, S_{F l a g}$ is the speed sensor fault flag, $S_{\text {Flag }}=1$ means that a speed sensor fault has been detected. It can be seen that if a speed sensor fault is detected, the estimated speed $\hat{\omega}_{r}$ will be used as feedback to the controller instead of the speed sensor information to implement a speed sensorless vector control, and speed sensor fault tolerance capability is obtained.

According to the analysis above, a unified criterion for speed and current sensor faults are summarized in Table I. Using this table, it is possible to determine which type of sensor failure occurred and to take corresponding maintenance measures for the induction motor control system.

\section{SIMULATION EXPERIMENTS}

Simulation experiments and results will be given in this section, and then the parameter determination method will be proposed.

\section{A. Simulation Experiments and Results}

To evaluate the performance of the proposed speed and current sensor FDI unit, a field oriented induction motor drive system is modeled. A fixed-step $(10 \mu \mathrm{s})$ Euler solver is employed to solve the system dynamic equations. The parameters of the induction motor are listed in Table II. The reference values for the d-aixs current and rotor flux are chosen as $i_{d}^{*}=1.9 \mathrm{~A}, \psi_{r}^{*}=L_{m} i_{d}^{*}=0.7398 \mathrm{~Wb}$. The gains of the three observers are all the same, $K_{P}=6, K_{I}=800, F_{s}=0.15$ and $F_{C}=10$.

Firstly, the performance of the proposed adaptive observer and the FDI unit are tested under healthy sensor conditions. In Fig. 4, the reference motor speed firstly rises from $0 \mathrm{rpm}$ to $1400 \mathrm{rpm}$ and decreases back to $0 \mathrm{rpm}$ at $2 \mathrm{~s}$, then it reverses to $-1400 \mathrm{rpm}$ and decreases back to $0 \mathrm{rpm}$ at $4 \mathrm{~s}$. It is obvious
TABLE II

PARAMETERS OF THE INDUCTION MOTOR

\begin{tabular}{|c|c|}
\hline Rated Power & $1.1 \mathrm{~kW}$ \\
Rated Speed & $1400 \mathrm{rpm}$ \\
Rated Voltage & $380 \mathrm{~V}$ \\
Rated Current & $2.8 \mathrm{~A}$ \\
Stator Resistance $\left(R_{s}\right)$ & $6.4985 \Omega$ \\
Rotor Resistance $\left(R_{r}\right)$ & $3.4289 \Omega$ \\
Stator Self-inductance $\left(L_{s}\right)$ & $411.3467 \mathrm{mH}$ \\
Rotor Self-inductance $\left(L_{r}\right)$ & $411.3467 \mathrm{mH}$ \\
Mutual Inductance $\left(L_{m}\right)$ & $389.3467 \mathrm{mH}$ \\
Pole Pairs $\left(n_{p}\right)$ & 2 \\
\hline
\end{tabular}

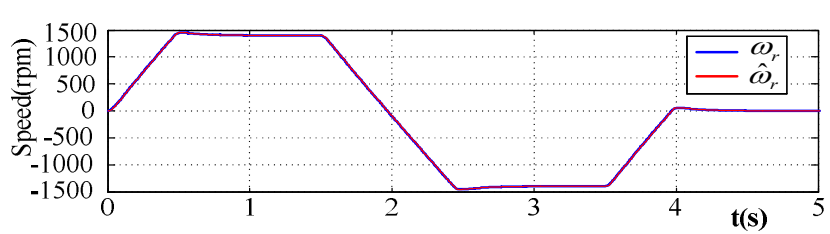

Fig. 4. Measured speed and the speed estimated by the proposed observer.

that the proposed observer can exactly estimate the motor speed whether it is in an acceleration or deceleration process.

In Fig. 5, the motor speed rises to $1400 \mathrm{rpm}$ at $0.5 \mathrm{~s}$, rated load is implemented at $1.5 \mathrm{~s}$ and is unloaded at $2.5 \mathrm{~s}$. Figure 5 shows that the observers work well during the loading and unloading periods. Although the current and speed sensor fault residuals are both influenced by the load, no fault is detected.

In the next test, the output of the b-phase current sensor is multiplied by zero at $1.5 \mathrm{~s}$ in order to simulate a failure. As shown in Fig. 6, $E_{1}$ and $E_{3}$ increase at $1.5 \mathrm{~s}$ and are much larger than $E_{2}$, and residual $\sigma$ is not affected. Since $\ell=2$, $I_{\text {Flag }}=1$ and $S_{\text {Flag }}=0$ after $1.5 \mathrm{~s}$, a b-phase current sensor fault is detected according to Table I. Most importantly, the measured and estimated speeds are not affected by the failure of the current sensor.

In Fig. 7, the output of the speed sensor is multiplied by zero at $1.5 \mathrm{~s}$ in order to simulate a speed sensor failure. It can be seen that the values of the residual $E_{1}, E_{2}, E_{3}$ and $\sigma$ all grow at $1.5 \mathrm{~s}$. Since $E_{1}, E_{2}$ and $E_{3}$ are close to each other, $I_{\text {Flag }}$ remains zero and a current sensor fault is not detected. However, since both $\sigma$ and $\bar{\sigma}$ are larger than $F_{s}$ at $1.5 \mathrm{~s}$, $S_{\text {Flag }}=1$ and a speed sensor fault is identified by the FDI unit. The estimated speed decreased a little after $1.5 \mathrm{~s}$ but soon returned to $1400 \mathrm{rpm}$.

From the above simulation experiments, it can be seen that the proposed adaptive observer and FDI unit are theoretically feasible and effective. More experimental work will be done in Section IV. 


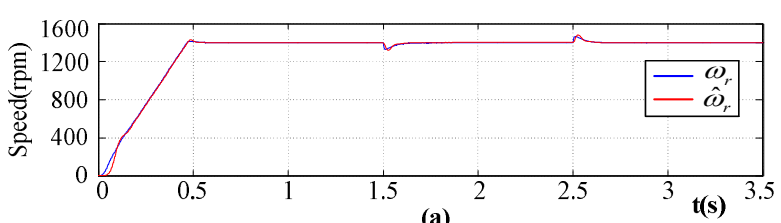

(a)
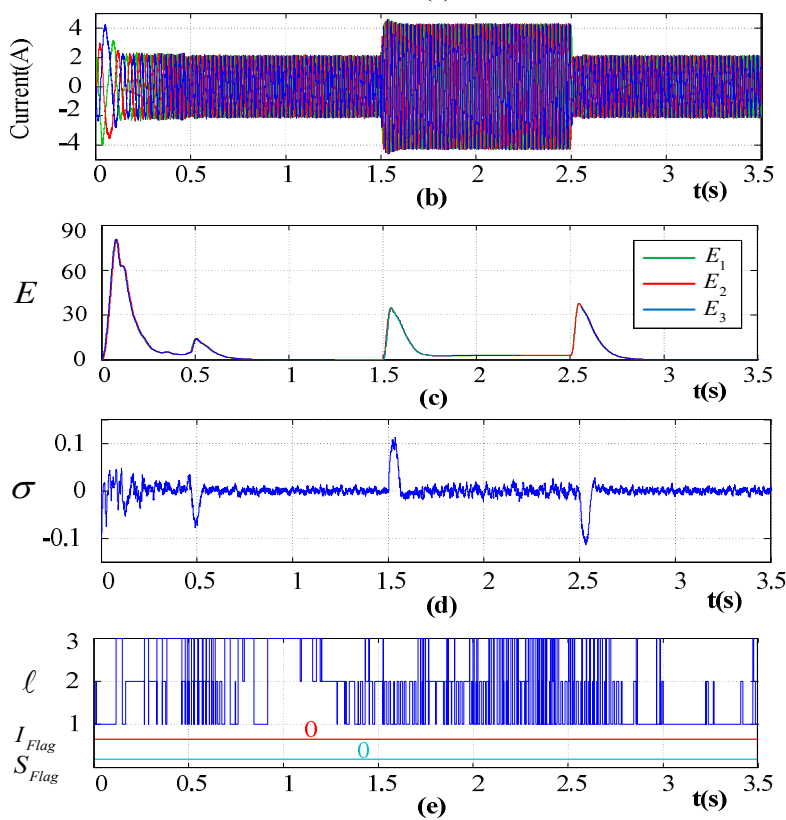

Fig. 5. Evaluation of the proposed observer and the FDI Unit under healthy sensor condition. (a) Measured and estimated speed $\left(\omega_{r}\right.$ and $\left.\hat{\omega}_{r}\right)$. (b) Stator currents $\left(i_{s a b, b}\right)$. (c) Current sensor fault residual $E_{1,2,3}$. (d) Speed sensor fault residual $\sigma$. (e) Fault flags.
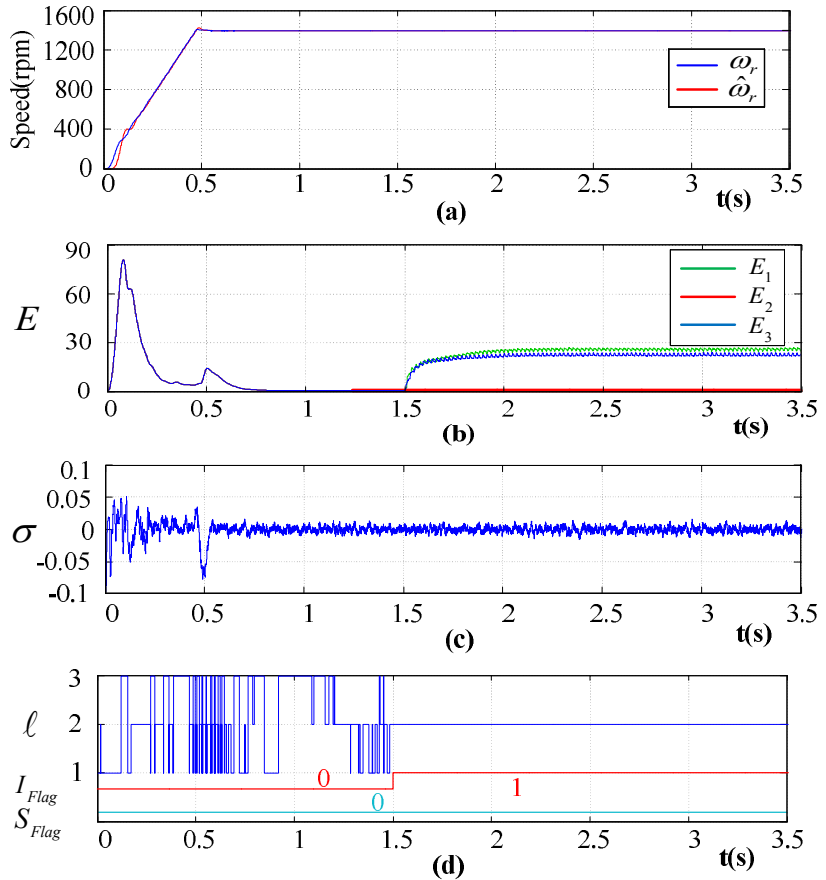

Fig. 6. Detection and isolation of b-phase current sensor fault. (a) Measured and estimated speed ( $\omega_{r}$ and $\left.\hat{\omega}_{r}\right)$. (b) Current sensor fault residual $E_{1,2,3}$. (d) Speed sensor fault residual $\sigma$. (e) Fault flags.

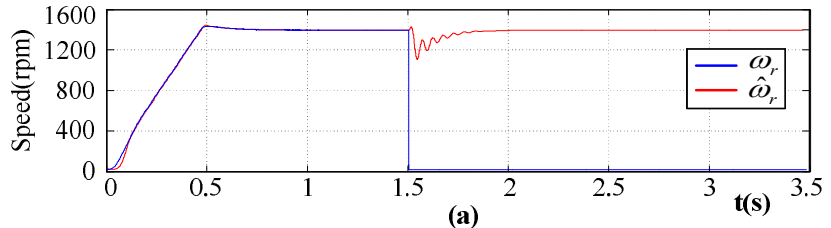

(a)
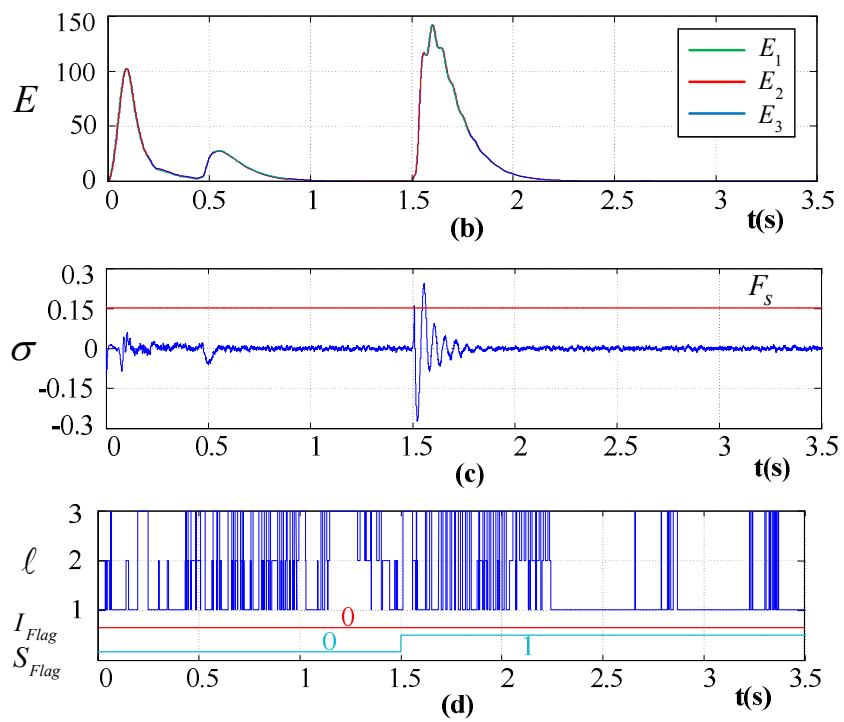

Fig. 7. Detection and isolation of speed sensor fault. (a) Measured and estimated speed ( $\omega_{r}$ and $\hat{\omega}_{r}$ ). (b) Current sensor fault residual $E_{1,2,3}$. (d) Speed sensor fault residual $\sigma$. (e) Fault flags.

\section{B. Parameter Determination}

Threshold $F_{s}$ and LPF time constant of $\sigma$ : At the instant of a speed sensor fault occurrence, $\sigma$ gets larger. Therefore, the residual value of d-axis current is taken as the criterion of a speed sensor fault. In addition, when the motor is suddenly impacted with a load, $\sigma$ will also get larger. As a result, the determination of the threshold $F_{\mathrm{s}}$ is related to the performance of the system. A low pass filter with a time constant of $\tau_{4}$ is used to extract the useful signal $\bar{\sigma}$ which is relevant to speed sensor faults. Fig. 8 shows the relationship between load percentage and $\bar{\sigma}$. In Fig. $8, \bar{\sigma}$ rises when the load is suddenly applied, and the maximum value is 0.08 when the rated load is suddenly applied. Experiment also shows that at the speed sensor fault instant, $\bar{\sigma}$ will be larger than 0.15 . Therefore, in order to detect speed sensor faults and avoid misinterpretations during load impaction or load release situations, the speed sensor fault threshold $F_{\mathrm{s}}$ is selected as 0.15 .

An experiment has been carried out to determine the low pass filter time constant $\tau_{4}$. In this experiment, the motor is operating at $50 \mathrm{~Hz}$, the full load is applied at $0.8 \mathrm{~s}$, and a speed sensor fault occurs at $1.5 \mathrm{~s}$.

Fig. 9 shows the FFT analysis result of $\sigma$ when a speed sensor fault occurs, where the FFT window width is 1 cycle (20ms, starting from the speed sensor fault instant). It can be 


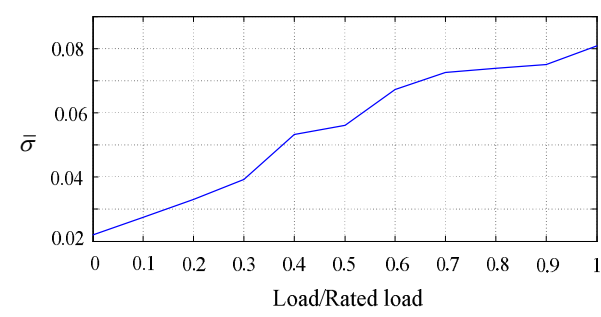

Fig. 8. Relationship between load percentages with $\bar{\sigma}$
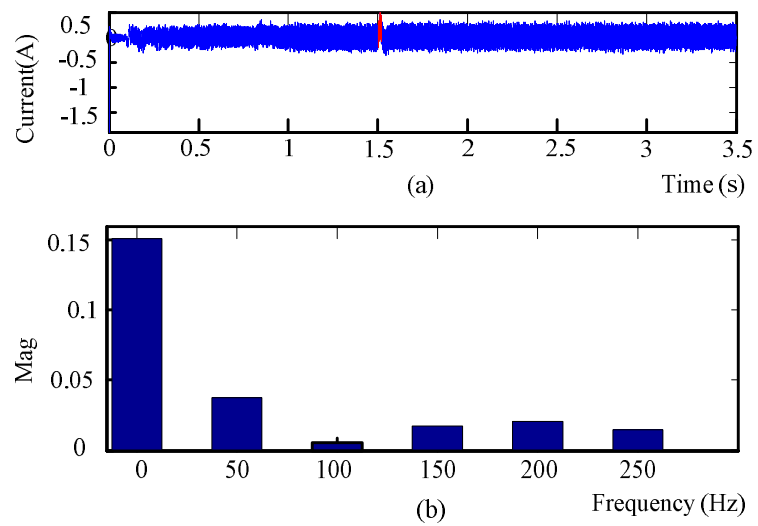

Fig. 9. FFT analysis result of $\sigma$ when speed sensor fault occurs
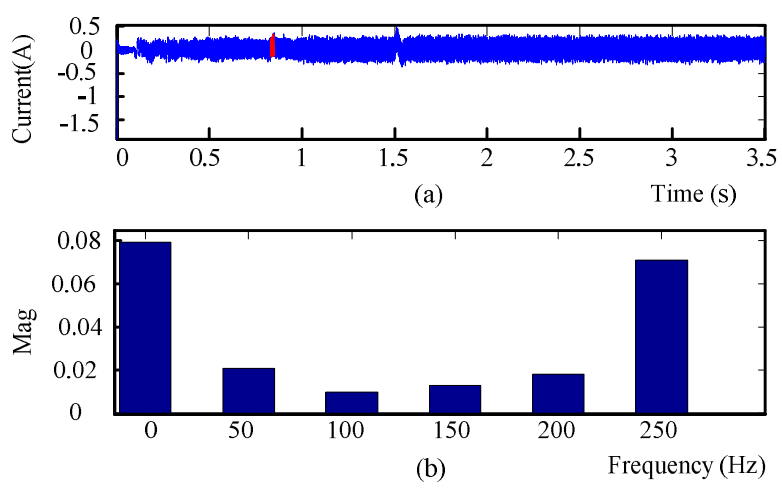

Fig. 10. FFT analysis result of $\sigma$ when rated load applied.

seen that during this cycle, the DC component of $\sigma$ is 0.15 and harmonics exist, but the amplitude is low.

Fig. 10 shows the FFT analysis result of $\sigma$ when the full load is applied. It can be seen that the DC component is only 0.08 .

According to Fig.9 and Fig.10, the low pass filter time constant $\tau_{4}$ can be set as 0.01 (the cut off frequency is $16 \mathrm{~Hz}$ ), since the difference in the DC component in this short cycle is enough to distinguish a speed sensor fault.

In the proposed system, the commonly used single sample and single update technique is adopted in the current control. The current loop bandwidth is $500 \mathrm{~Hz}$, and the speed control loop bandwidth is $44 \mathrm{~Hz}$. For other general motor drive systems with a higher bandwidth and a faster dynamic response, the current variation speed will be faster, and it will take less time to reach the threshold. Even when the proposed method is used in other general motor drive systems with higher bandwidth, the high frequency components of $\sigma$ induced by a higher bandwidth loop can be attenuated by a LPF. Therefore, the key point is selecting a low cutoff frequency LPF, since this can almost make the scheme irrelevant to the system bandwidth. The proposed scheme is also adaptable to other general motor drive systems.

Threshold $F_{c}$ and LPF time constants of $\hat{\omega}_{\mathrm{r}}, \hat{\psi}_{\mathrm{r}}$ and $E_{j}$ : In order to diagnose the current sensor faults, the residual variable, as shown in equation (21), are considered. Unfortunately, $E_{\mathrm{j}}$ is also sensitive to system performance factors such as overshoot and load application dynamics. Experiments have been carried out in order to evaluate how much the dynamics affect $E_{\mathrm{j}}$ when compared with current sensor faults.

Fig. 11 shows the experimental results. Firstly, the motor is operating at $30 \mathrm{~Hz}$ at the no-load condition, then the full load is impacted at $2.7 \mathrm{~s}$, and released at $5.8 \mathrm{~s}$. A b phase current sensor fault occurs at $9 \mathrm{~s} . E_{1}, E_{2}, E_{3}$ are obtained from observer 1 , observer 2 , observer 3 , respectively. $\mathrm{B}$ and $\mathrm{C}$ phase current sensors are used in observer $1, \mathrm{~A}$ and $\mathrm{C}$ phase current sensors are used in observer 2 , and $\mathrm{A}$ and $\mathrm{B}$ phase current sensors are used in observer 3.

It can be seen that the load impact and release influence $E_{\mathrm{j}}$ due to the fact that the overshoot of the estimated $\hat{\omega}_{\mathrm{r}, \mathrm{j}}$ deviated from the reference value $\omega^{*}$, and the estimated flux $\hat{\psi}_{\mathrm{r}, \mathrm{j}}$ deviated from the reference value. Even so, the deviations can be compensated by each other, $E_{1}-E_{2}, E_{1}-E_{3}$ and $E_{3}-E_{2}$ tend to be zero.

At $9 \mathrm{~s}$, a B phase current sensor fault occurs. As a result, $E_{1}$ and $E_{3}$ get larger since their corresponding observers rely on a faulty current sensor. $E_{2}$ still stays zero since the phase A and phase $\mathrm{C}$ current sensors are healthy. Thus, according to the current sensor fault diagnosis rules proposed in this paper, $E_{1}>E_{2}, E_{3}>E_{2}$ and $E_{1}-E_{2}>F_{c}$, a B phase current sensor fault is detected.

From the analysis above, it can be concluded that dynamic characteristics such as the overshoot, load disturbance, etc. can be automatically compensated by three consistent observers, and that they will not induce current sensor fault misinterpretation. When certain current sensor fault occurs, they can be diagnosed and localized by the inconsistence output of the three observers.

The threshold is easy to determine, since a current sensor fault can induce a relatively large imbalance. From the waveforms in Fig. 11(f), $F_{\mathrm{C}}=10$ is selected. The low pass filter time constant of $\hat{\omega}_{\mathrm{r}, \mathrm{j}}$ and $\hat{\psi}_{\mathrm{r}, \mathrm{j}}$ can be selected according to the system noise level. It is suitable for them to be in the range of $0.001 \sim 0.01$, as long as they are the same in all three observers.

As to the determination of $\tau_{3}$, which is the LPF time constant of $E_{\mathbf{j}}$, it can be seen in Fig. $9(\mathrm{c})$ that the DC 


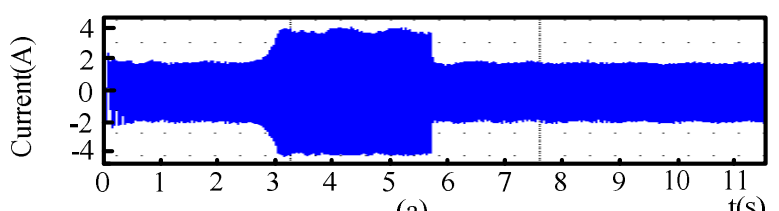

(a)

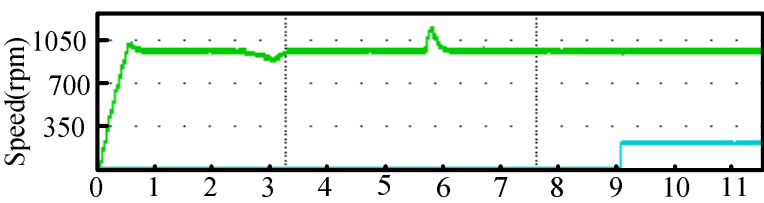

(b) $\mathrm{t}(\mathrm{S})$

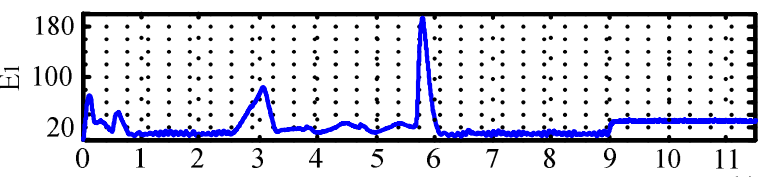

(c) $\mathrm{t}(\mathrm{s})$

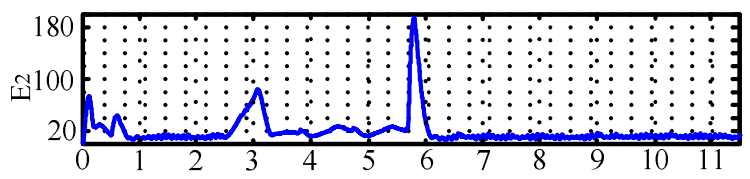

(d) t(s)

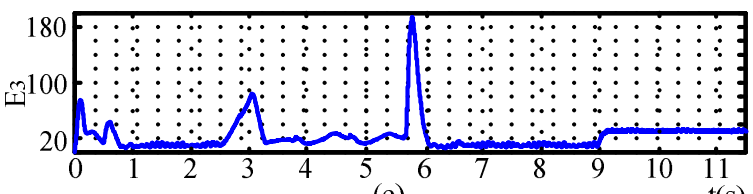

(e)

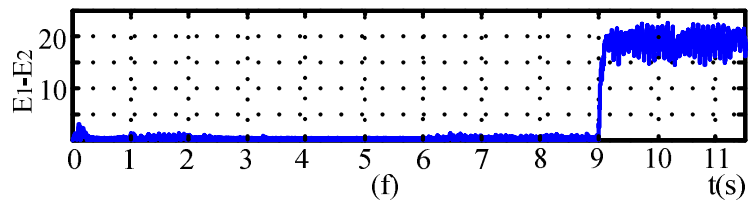

Fig. 11. Comparison of the influence on $E_{\mathrm{j}}$

component is the majority component after a current sensor fault occurrence. Therefore, the low pass filter time constant is selected as 0.05 to reserve the DC component and attenuate harmonics.

\section{EXPERIMENTAL SETUP AND RESULTS}

In order to investigate the performance of the proposed fault detection and isolation scheme under different operating conditions, experimental tests are carried out with a $1.1 \mathrm{kw}$ three-phase induction motor platform based on a dSPACE DS1104 board.

A schematic of the experimental platform is shown in Fig. 12. The experimental platform consists of two induction motors and two inverters. Motor 1, which is controlled by Inverter 1 , is to be tested. Motor 2 works as the load torque for Motor 1 and is controlled by an ABB ACS800 inverter which works under the Direct Torque Control (DTC) mode. In order to feedback the energy, the DC buses of the two inverters are connected in parallel. The two motors are the same and their parameters are listed in Table II.

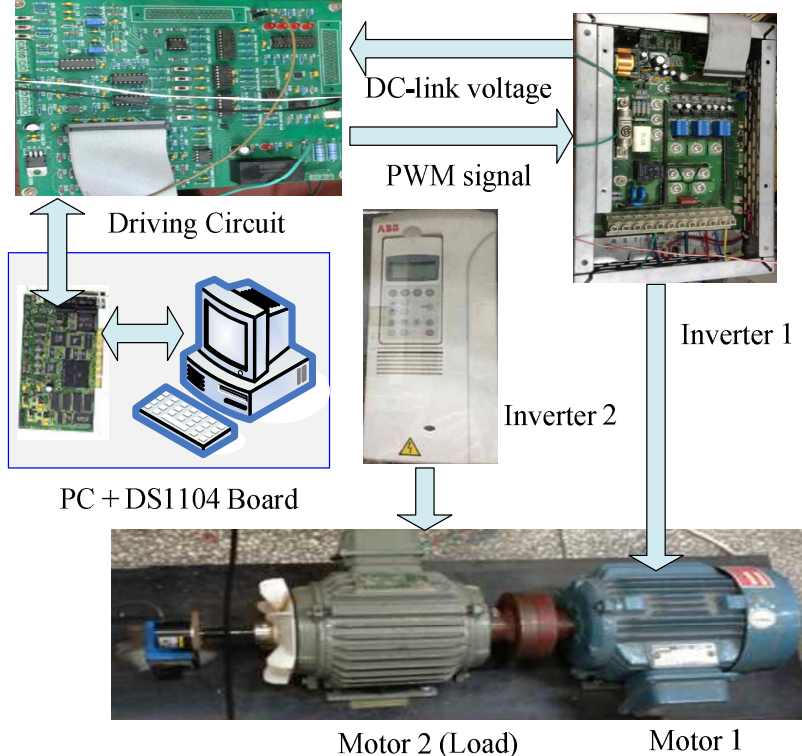

Fig. 12. Schematic of the experimental platform.

The parameters of the observers and the FDI unit are the same as those used in the simulation tests, as reported in Section III, except that the sampling period is $T_{s}=0.15625 \mathrm{~ms}$. By using the proposed threshold determination method, the fault thresholds $F_{s}=0.04$ and $F_{c}=10$, and the reference signal for the motor speed is a ramp that starts from zero at $t=1 \mathrm{~s}$ and reaches the desired value $\omega_{r}^{*}=1400 \mathrm{rpm}$ at $t=1.5 \mathrm{~s}$.

In the following experiments, the failures of the sensors are simulated by a software method. That is, the output signal of a certain sensor is multiplied by zero if this sensor is expected to fail. Thus, sensor faults can be simulated without destroying the hardware configuration of the sensors.

In the first test, the motor is running without load. A speed sensor fault is imposed at $4 \mathrm{~s}$ and a b-phase current sensor fault is imposed at 6s, as shown in Fig. 13. Since the residual $\sigma$ is greater than the speed sensor fault threshold $F_{s}$ at 4 s, $S_{\text {Flag }}=1$ and a fault in the speed sensor is detected and isolated. At $6 \mathrm{~s}$, since $I_{F l a g}=1$ and $\ell=1$, a fault in the c-phase current sensor is detected and isolated. From Fig. 13(a), it can be seen that the motor can keep running with good performance with faulty sensors.

The second test is similar to test 1 , except that a c-phase sensor fault is imposed before the speed sensor fault, as shown in Fig. 14. By comparing test 2 to test 1, it can be seen that under the no load operation, the FDI scheme can effectively detect and isolate speed and current sensor faults immediately in turn, no matter which one occurs first. The occurrence of one kind of sensor fault does not affect the detection and isolation of the other one.

In the third test, sensor faults are imposed during the dynamic process of the motor, and the speed sensor fault 


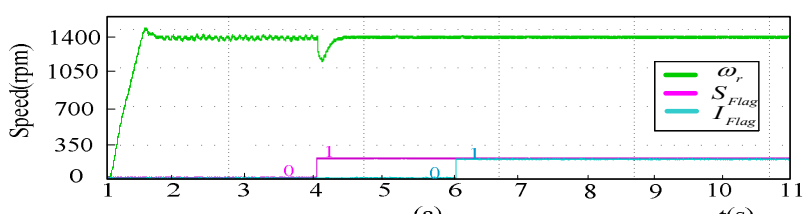

(a)

$\mathrm{t}(\mathrm{s})$
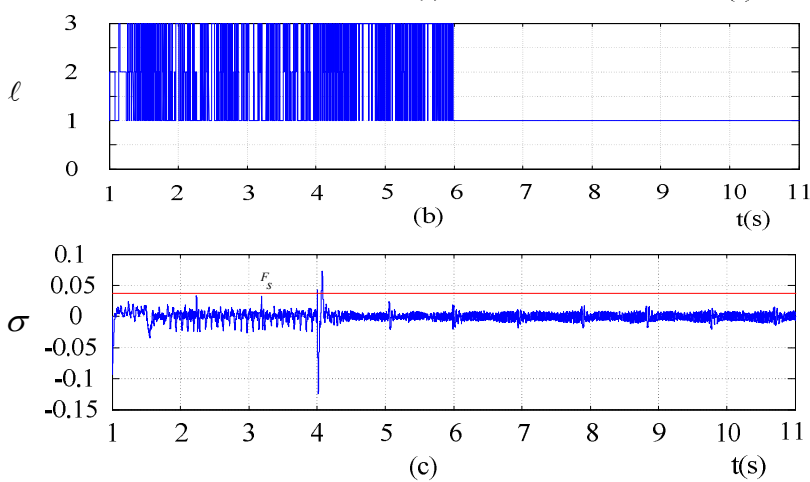

Fig. 13. Waveforms of $\omega_{r}, S_{\text {Flag }}, I_{\text {Flag }}, \ell$ and $\sigma$ when the motor is running without load and the speed sensor fault occurs before the c-phase current sensor fault.
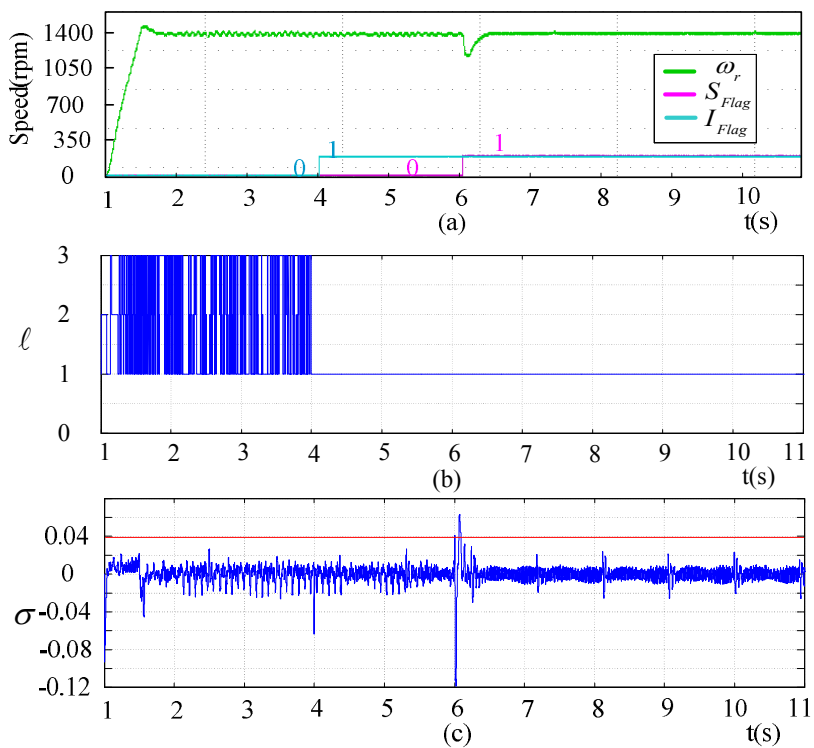

Fig. 14. Waveforms of $\omega_{r}, S_{\text {Flag }}, I_{\text {Flag }}, \ell$ and $\sigma$ when the motor is running without load and the c-phase current sensor fault occurs before the speed sensor fault.

occurs before the b-phase current sensor fault, as shown in Fig. 15. Similarly, in the fourth test, sensor faults are also imposed during the dynamic process of the motor but the bphase current sensor fault occurs before the speed sensor fault, as shown in Fig. 16. It can be seen that the proposed FDI scheme works well during the dynamic process and that the sensor faults can be successfully detected and isolated.

In test 5 , a $100 \%$ load is implemented to the motor at $2 \mathrm{~s}$ (load torque acceleration time is $0.01 \mathrm{~s}$ ), a fault in the speed sensor is imposed at $4 \mathrm{~s}$ and a fault in the b-phase current sensor is imposed at $6 \mathrm{~s}$, as shown in Fig. 17. Meanwhile, in the next test, the fault in the b-phase current sensor is

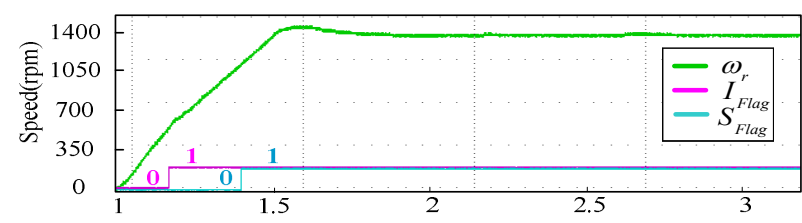

(a)

$\mathrm{t}(\mathrm{s})$

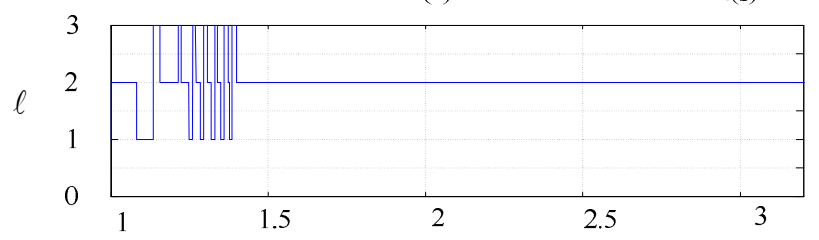

(b)

$\mathrm{t}(\mathrm{s})$

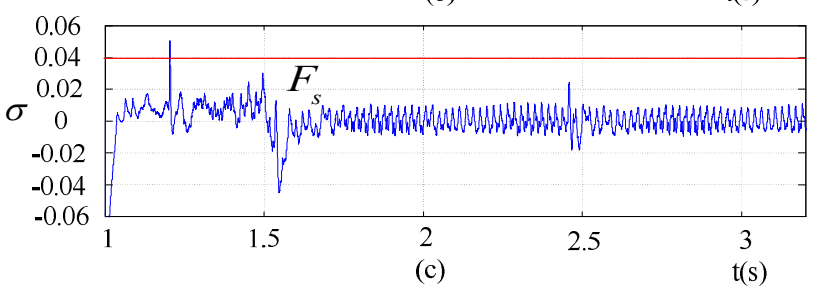

Fig. 15. Waveforms of $\omega_{r}, S_{\text {Flag }}, I_{\text {Flag }}, \ell$ and $\sigma$ when sensor fault occurs during the start-up process of the motor and the speed sensor fault occurs before the b-phase current sensor fault.
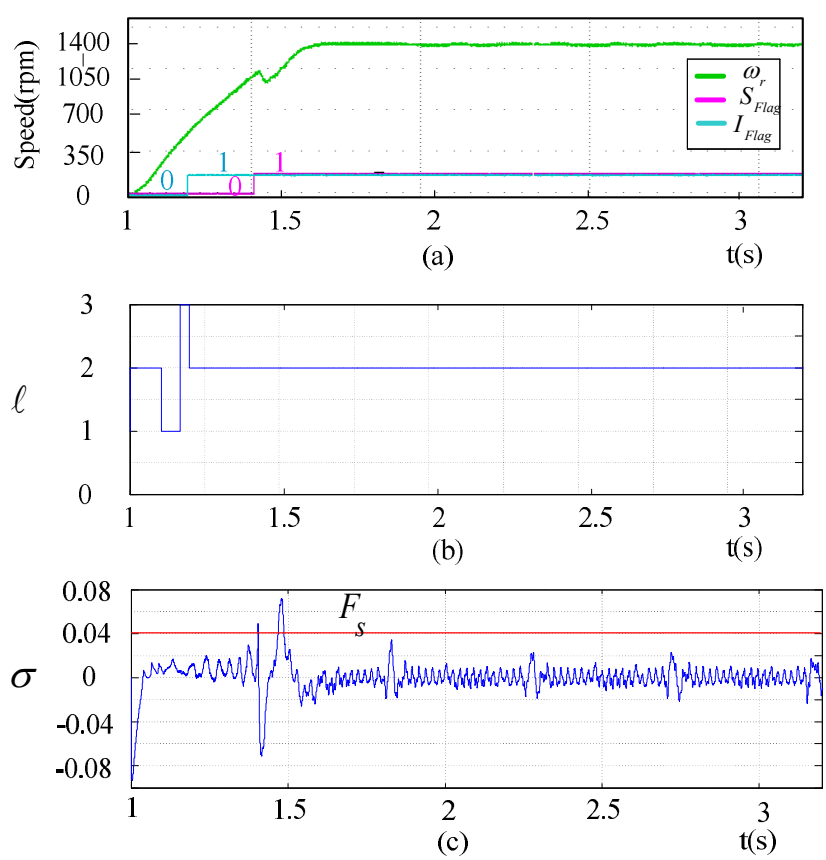

Fig. 16. Waveform of $\omega_{r}, S_{\text {Flag }}, I_{\text {Flag }}, \ell$ and $\sigma$ when sensor fault occurs during the start-up process of the motor and the bphase current sensor fault occurs before the speed sensor fault.

imposed at $4 \mathrm{~s}$ and the fault in the speed sensor is imposed at $6 s$, as shown in Fig. 18. Although the sequence of the speed and current sensor faults are different in these two tests, the detection and isolation of the faults is not influenced.

In test 6 , the fault diagnosis and tolerant control are tested at a full load, $5 \mathrm{~Hz}$ condition. The speed sensor fault is imposed at $3 \mathrm{~s}$ and the b-phase current senor fault is imposed at $6 \mathrm{~s}$, as shown in Fig. 19. Experiments show that with the 

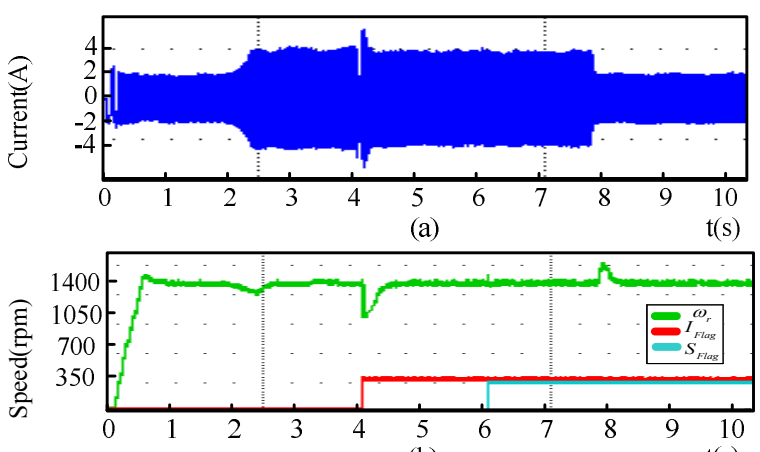

(b) $\mathrm{t}(\mathrm{s})$

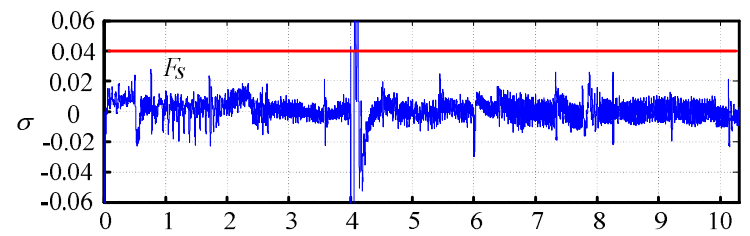

(c) $\mathrm{t}(\mathrm{s})$

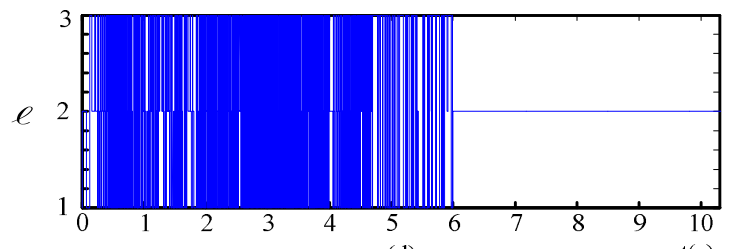

(d)

$\mathrm{t}(\mathrm{s})$

Fig. 17. Waveform of current, $\omega_{r}, S_{\text {Flag }}, I_{\text {Flag }}, \ell$ and $\sigma$ when the motor is running with $100 \%$ load and the speed sensor fault occurs before the b-phase current sensor fault.
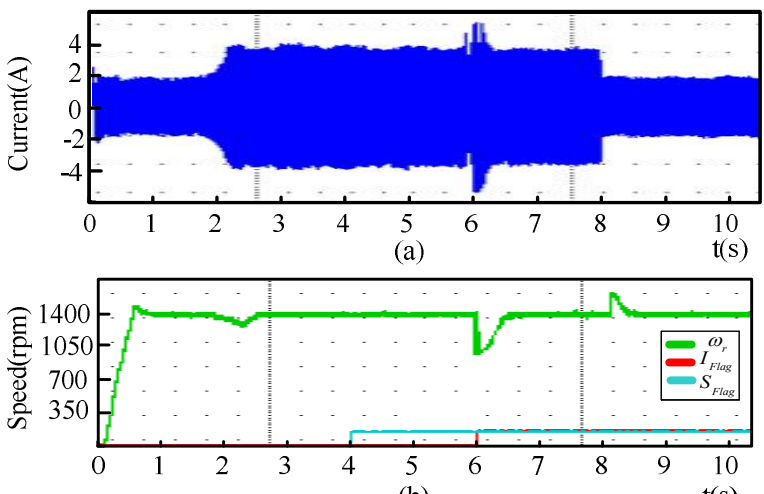

(b)

$\mathrm{t}(\mathrm{s})$

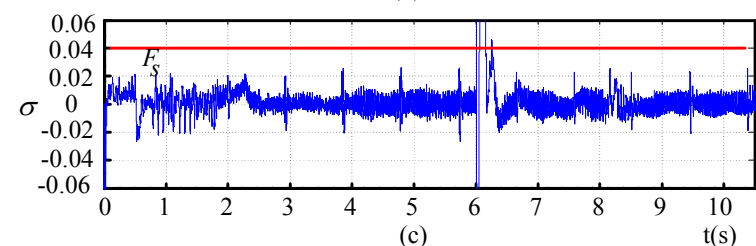

(c)

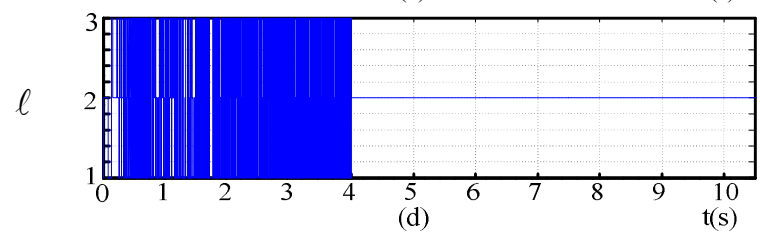

(d)

Fig. 18. Waveform of current, $\omega_{r}, S_{\text {Flag }}, I_{\text {Flag }}, \ell$ and $\sigma$ when the motor is running with $100 \%$ load and the b-phase current sensor fault occurs before the speed sensor fault.
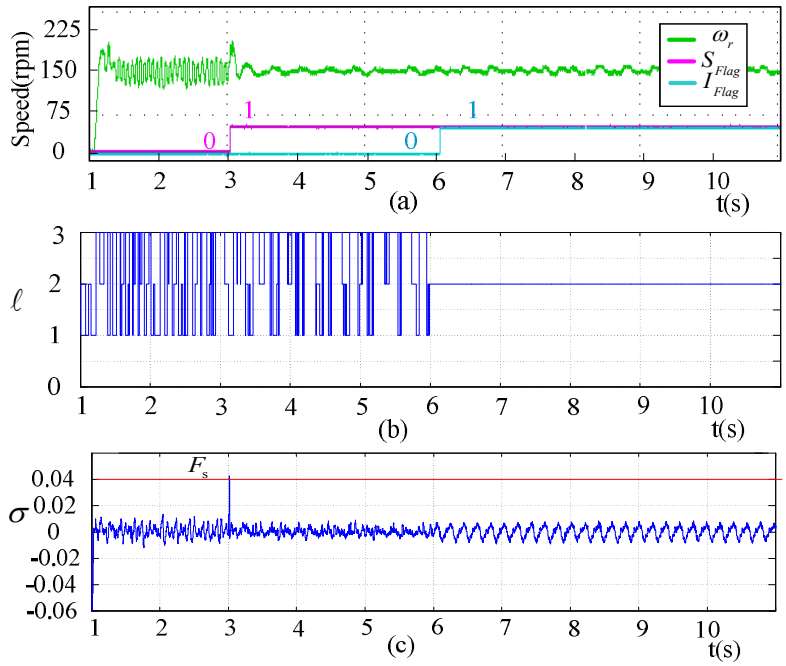

Fig. 19. Waveform of $\omega_{r}, S_{\text {Flag }}, I_{\text {Flag }}, \ell$ and $\sigma$ when the motor is running at $5 \mathrm{~Hz}$, full load and the speed sensor fault occurs before the b-phase current sensor fault

proposed method, the FDI units are also feasible in such critical situations. Due to the fact that the motor shaft is not well aligned with the encoder shaft, the speed control performance with speed sensor feedback is even worse than the speed sensorless scheme. Anyway, it is related to the mechanical setup, and the feasibility of the proposed speed and current sensor fault diagnosis and tolerant control is not affected.

\section{CONCLUSIONS}

A FDI scheme based on three adaptive observers has been proposed for the detection and isolation of speed and current sensor faults in induction motor drives. Using the proposed adaptive observers, the phase currents, rotor flux and motor speed can be estimated. The convergence of the proposed observer is proved theoretically. Extensive simulation and dSPACE based experiments are implemented to verify the effectiveness of the FDI scheme. The experimental results show that the detection result is not affected by changes of the load torque, and that sensor faults that occur during the dynamic process of the motor can also be detected. The most important thing is the fact that the failure of one sensor will not influence the detection and isolation of the other kind of sensor fault.

\section{ACKNOWLEDGMENT}

This work was supported by National Natural Science Foundation of China (Project 51377032).

\section{REFERENCES}

[1] S. Nandi, "Detection of stator faults in induction machines using residual saturation harmonics," IEEE Trans. Ind. Appl., Vol. 42, No. 5, pp. 1201-1208, Sep./Oct. 2006. 
[2] A. Siddique, G. S. Yadava, and B. Singh, "A review of stator fault monitoring techniques of induction motors," IEEE Trans. Energy Convers., Vol. 20, No. 1, pp. 106-114, Mar. 2005.

[3] G. Y. Sizov, A. Sayed-Ahmed, C.-C. Yeh, and N. A. O. Demerdash, "Analysis and diagnostics of adjacent and nonadjacent broken-rotor-bar faults in squirrel-cage induction machines," IEEE Trans. Ind. Electron., Vol. 56, No. 11, pp. 4627-4641, Nov. 2009.

[4] G. R. Bossio, C. H. De Angelo, G. O. Garcia, J. A. Solsona, and M. I. Valla, "Effects of rotor bar and end-ring faults over the signals of a position estimation strategy for induction motors," IEEE Trans. Ind. Appl., Vol. 41, No. 4, pp. 1005-1012, Jul./Aug. 2005.

[5] S. Li and L. Xu, "Strategies of fault tolerant operation for three-level PWM inverters," IEEE Trans. Power Electron., Vol. 21, No. 4, pp. 933-940, Jul. 2006.

[6] F. Immovilli, A. Bellini, R. Rubini, and C. Tassoni, "Diagnosis of bearing faults in induction machines by vibration or current signals: A critical comparison," IEEE Trans. Ind. Appl., Vol. 46, No. 4, pp. 1350-1359, Jul./Aug. 2010.

[7] A. Ibrahim, M. El Badaoui, F. Guillet, and F. Bonnardot, "A new bearing fault detection method in induction machines based on instantaneous power factor," IEEE Trans. Ind. Electron., Vol. 55, No. 12, pp. 4252-4259, Dec. 2008.

[8] S. Nandi, T. C. Ilamparithi, S. B. Lee, and D. Hyun, "Detection of eccentricity faults in induction machines based on nameplate parameters," IEEE Trans. Ind. Electron., Vol. 58, No. 5, pp. 1673-1683, May 2011.

[9] M. Blodt, J. Regnier, and J. Faucher, "Distinguishing load torque oscillations and eccentricity faults in induction motors using stator current wigner distributions," IEEE Trans. Ind. Appl., Vol. 45, No. 6, pp. 1991-2000, Nov./Dec. 2009.

[10] A. Bellini, F. Filippetti, C. Tassoni, and G.-A. Capolino, "Advances in diagnostic techniques for induction machines," IEEE Trans. Ind. Electron., Vol. 55, No. 12, pp. 4109-4126, Dec. 2008.

[11] T. A. Najafabadi, F. R. Salmasi, and P. Jabehdar-Maralani, "Detection and isolation of speed-, DC-link voltage-, and current-sensor faults based on an adaptive observer in induction-motor drives," IEEE Trans. Ind. Electron., Vol. 58, No. 5, pp. 1662-1672, May 2011.

[12] J. Guzinski, M. Diguet, Z. Krzeminski, A. Lewicki, and H. Abu-Rub, "Application of speed and load torque observers in high-speed train drive for diagnostic purposes," IEEE Trans. Ind. Electron., Vol. 56, No. 1, pp. 248-256, Jan. 2009.

[13] C. Lascu, I. Boldea, and F. Blaabjerg, "A class of speedsensorless sliding-mode observers for high-performance induction motor drives," IEEE Trans. Ind. Electron., Vol. 56, No. 9, pp. 3394-3403, Sep. 2009.

[14] T. Orlowska-Kowalska and M. Dybkowski, "Stator-currentbased MRAS estimator for a wide range speed-sensorless induction-motor drive," IEEE Trans. Ind. Electron., Vol. 57, No. 4, pp. 1296-1308, Apr. 2010.

[15] M. Barut, S. Bogosyan, and M. Gokasan, "Speed-sensorless estimation for induction motors using extended kalman filters," IEEE Trans. Ind. Electron., Vol. 54, No. 1, pp. 272280, Feb. 2007

[16] F. Zidani, D. Diallo, M.E.H. Benbouzid, and E. Berthelot, "Diagnosis of speed sensor failure in induction motor drive," IEEE International Conference on Electric Machines and Drives, Vol. 2, pp. 1680-1684, May 2007.

[17] S. Fan and J. Zou, "Sensor fault detection and fault tolerant control of induction motor drivers for electric vehicles," 2012 7th International Power Electronics and Motion Control Conference, Vol. 2, pp. 1306-1309, Jun. 2012.

[18] M. E. Romero and M. M. Seron, "Speed-sensorless control of induction motors with improved fault tolerance against current sensor failure," 18th Mediterranean Conference on Control and Automation, pp. 515-520, Jun. 2010.

[19] H. Berriri, M. W. Naouar, and I. Slama-Belkhodja, "Easy and fast sensor fault detection and isolation algorithm for electrical drives," IEEE Trans. Power Electron., Vol. 27, No. 2, pp. 490-499, Feb. 2012.

[20] H. Kubota, K. Matsuse, and T. Nakano, " DSP-based adaptive flux observer of induction motor," IEEE Trans. Ind. Appl., Vol. 29, No. 2, pp. 344-348, Mar./Apr. 1993

[21] A. Abbou, Y. Sayouti, H. Mahmoudi, and M. Akherraz, "dSPACE direct torque control implementation for induction motor," 2010 18th Mediterranean Conference on Control and Automation, pp. 1121-1126, Jun. 2010.

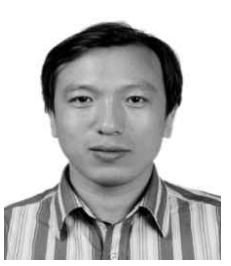

Yong Yu was born in Jilin Province, China, in 1974. He received his B.S. degree in Electromagnetic Measurement and Instrumentation from the Harbin Institute of Technology (HIT), Harbin, China, and his M.S. and Ph.D. degrees in Electrical Engineering from HIT, in 1997 and 2003, respectively. Since 2004, he has been an Associate Professor in the Department of Electrical Engineering, HIT. His current research interests include electrical motor drives, power quality mitigation, and fault diagnosis and tolerant control of inverters.

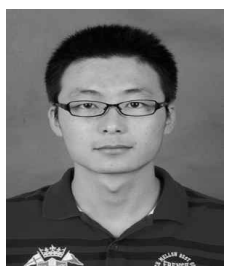

Ziyuan Wang was born in 1989. He received his B.S. degree in Electrical Engineering from Yanshan University, Qinhuangdao, China. $\mathrm{He}$ is presently working toward his M.S. degree at the Harbin Institute of Technology (HIT), Harbin, China. His current research interests include fault diagnosis and tolerant control of

inverters.

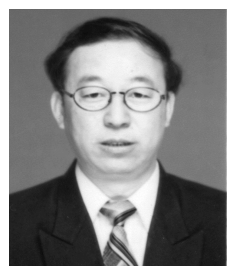

Dianguo Xu (M'97, SM'12) received his B.S. degree in Control Engineering from Harbin Engineering University, Harbin, China, in 1982, and his M.S. and Ph.D. degrees in Electrical Engineering from Harbin Institute of Technology (HIT), Harbin, China, in 1984 and 1989 respectively. In 1984, he joined the Department of Electrical Engineering, HIT as an Assistant Professor. Since 1994, he has been a Professor in the Department of Electrical Engineering, HIT. He was the Dean of the School of Electrical Engineering and Automation, HIT, from 2000 to 2010. $\mathrm{He}$ is now the Vice President of HIT. His current research interests include renewable energy generation technology, multiterminal HVDC systems based on VSC, power quality mitigation, speed sensorless vector controlled motor drives, and high performance PMSM servo systems. He has published over 600 technical papers. Dr. Xu is a Senior Member of the IEEE, an Associate Editor for the IEEE Transactions on Industrial 
Electronics. He serves as the Chairman of the IEEE Harbin Section, the Director of the Lighting Power Supply Committee of the CPSS, the Vice-director of the Electric Automation Committee of the CAA, the Electrical Control System and Equipment Committee of the CES, and the Power Electronics Committee of the CES.

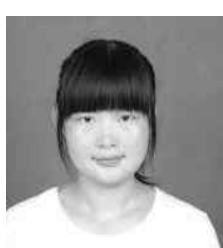

Tao Zhou was born in 1988. She received her B.S. degree in Electrical Engineering from Harbin Institute of Technology (HIT), Weihai, China, in 2011, and her M.S. degree in Electrical Engineering from Harbin Institute of Technology (HIT), Harbin, China, in 2013. She is presently working toward her Sciences, Beijing, China.

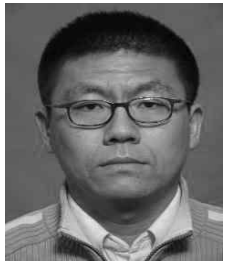

Rong Xu was born in Jilin Province, China, in 1984. He received his B.S. degree in Applied Physics from the Harbin University of Science and Technology, Harbin, China, in 2007, and his M.S. degree in Power Machinery and Engineering from Harbin Institute of Technology (HIT), Harbin, China, in 2009. $\mathrm{He}$ is currently working toward his $\mathrm{Ph} . \mathrm{D}$. degree in Electrical Engineering at HIT. His current research interests include highpower power electronics, multilevel converters and power quality mitigation. 